\title{
Restricting microplastics in the European Union: Process and criteria under $\mathrm{REACH}^{\star}$
}

\author{
Esther Kentin ${ }^{\mathrm{a}}$ \\ Institute of Interdisciplinary Studies, Leiden Law School, Leiden University, Leiden, The Netherlands
}

Received: 28 May 2018 / Revised: 13 July 2018

Published online: 18 October 2018

(c) The Author(s) 2018. This article is published with open access at Springerlink.com

\begin{abstract}
As part of the EU Plastics Strategy, the European Commission has initiated the restriction process regarding intentionally added microplastics under REACH (acronym of the EU chemical regulation). A restriction dossier is compiled by ECHA according the provisions of REACH. Not only environmental and health risk assessments have to be made, but a large part of the dossier concerns socio-economic analyses and evaluations of risk management options, in order to justify a Union-wide restriction. The procedure reflects the multiple objectives of REACH: protection of human health and the environment, but also the functioning of the internal market. Although the precautionary principle is incorporated in REACH, it plays a less than subordinate role. The process of restriction offers interested parties the possibility to present information and evidence. For the restriction dossier on microplastics is of utmost importance that all available evidence is provided. When less data is available, restriction seems to be less likely.
\end{abstract}

\section{Introduction}

In November 2017, the European Commission requested the European Chemical Agency (ECHA) to prepare a restriction dossier on microplastics, thereby starting the restriction procedure under REACH, the EU chemicals regulation [1, 2]. This decision follows the conclusion of a study on intentionally added microplastics, which was instigated by the request of several Member States and commissioned in 2015 (EC Report on Microplastics) [3]. Moreover, national legislation and proposals thereto, of France, Sweden and Belgium in 2016 and 2017, triggered the request for a restriction dossier. The EU Plastics Strategy, published in January 2018, further built up the momentum for the regulation of plastics in general [4]. This article looks into the process and steps of the restriction process under REACH, in particular on restricting microplastics in cosmetics products, as it will be most likely that, at least, this restriction measure will be proposed. Although covering only a limited fraction of the intentionally added microplastics, microplastics in cosmetic products are relatively easy to phase out and are already regulated by national measures. However, the request for a restriction dossier and the EC Report on Microplastics go beyond microplastics in cosmetic products, as environmental hazards of other products with microplastics are likely to be the same. Besides, microplastics emitted in the environment, not intentionally added, but generated during the life cycle of product, likewise form a threat to the environment, a matter also under attention of the European Commission [5].

This article is written from a law-making perspective and its purpose is to provide scientists with a better understanding how EU law-making works, in particular in the case of restricting microplastics. The interaction between scientific evidence and policy-making is, of course, not a new phenomenon, and scientific research has invoked policy change in the past [6]. This article addresses in particular the REACH restriction procedure. The input of science is institutionalised by the creation of scientific committees, in particular the Committee for Risk Assessment and the Committee for Socio-economic Analysis. Also scientific studies are extensively used for compiling the restriction dossier. It points out the interaction between policy making and science: without scientific evidence no restriction in REACH can be adopted. But, as the article also establishes, the final decision remains in political hands.

\footnotetext{
* Focus Point on "Microplastic Pollution: Assessment, Effects and Mitigation Strategies" edited by M. Avella, R. Avolio, M. Cocca, E. Di Pace, M. E. Errico, G. Gentile

a e-mail: e.kentin@law.leidenuniv.nl
} 


\section{REACH regulation}

REACH is the chemical regulations of the European Unions (EU) adopted in 2006 and regulates the registration, evaluation, authorisation and restriction of chemical substances. According to Article 1 REACH, its aims are protection of human health and environment and internal market and its provisions are underpinned by the precautionary principle. REACH replaces the rather ad-hoc approach of previous EU regulation on chemicals, which was based on responding on problems that emerged [7]. REACH is complemented by the Regulation on the classification, labelling and packaging of substances (CLP Regulation) [8].

The building blocks of REACH are the procedures of registration, evaluation, authorisation and restriction. A substance can only enter the EU market when is has been registered by the manufacturer or importer, the so-called "no data, no market" rule, included in Article 5 REACH. The manufacturer or importer of a substance has to submit a technical dossier for registration according Article $10 \mathrm{REACH}$, the registration dossier. Polymers have been exempted according from this rule according Article 6.3 REACH, if its monomers substances have been registered.

Evaluation pertains to dossier and substance evaluation. There are two types of dossier evaluations: the examination of testing proposals for conducting tests on vertebrate animals to prevent unnecessary testing, and the compliance check of at least $5 \%$ of registration dossiers. Substance evaluation will be carried out by Member States after placing the substance on a priority list, based on risk and hazards, as defined by Article 44 REACH. The results of substance evaluation can lead to further regulatory steps, such as authorisation, restriction, voluntary actions or measures under other EU legislation.

The authorisation procedure can be started when a substance is listed or marked as a substance of very high concern (SVHC). Generally, this is the case if a substance can be classified as carcinogenic, mutagenic or toxic for reproduction (CMRs), or as persistent, bioaccumulative and toxic (PBT), or as very persistent and very bioaccumulative (vPvB) or for which equivalent concerns exist (Article $57 \mathrm{REACH}$ ). The authorisation procedure is aiming at substituting these substances with less dangerous alternatives, in subsequent phases. After the so-called sunset date, the use of the substance has to be authorised by the European Commission, which can be done under certain conditions and until further review. Authorisation does not apply to substances in products and would therefore not be suitable for regulating microplastics in certain products [9].

Restriction of a substance is initiated when there is an unacceptable risk to human health or the environment, arising from the manufacture, use or placing on the market of substances, which needs to be addressed on a Community-wide basis (Article $68 \mathrm{REACH}$ ). In that case, Annex XVII REACH, listing all restrictions, will be amended according to the restriction process and legislative procedure described further in this article.

REACH provides for several exemptions, which can be general or partial. Certain substances can be exempted from certain procedures, such as registration, or REACH may not be applicable to certain products or in certain cases. Regarding microplastics, it is important to note that polymers, as substances are completely exempted from registration and evaluation, if its building blocks, monomers, have been registered according Article 6.3 REACH [10]. At the time of adopting REACH, in several jurisdictions, such as the US and Japan, the concept of polymers of low concern was used to reduce regulatory requirements for the majority of polymers [11]. Although the approach of $\mathrm{REACH}$ is totally different from those in these jurisdictions - in particular the pre-registration requirement for any substance, harmful or not-, a general exemption for polymers was incorporated. To end this exemption and to bring polymers under the registration regime, the European Commission may initiate a specific procedure of Article 138 $\mathrm{REACH}$ : the Commission first has to compile a report on the risks of polymers and the need for registration, and then it may, if there is a practical and cost-efficient way of selecting polymers, propose an amendment to include polymers for registration.

Other exceptions are based on overlap with other regulations. This is the case regarding microplastics in cosmetic products: also the Cosmetics Regulation applies [12]. The Cosmetic Regulation regulates the safety for human health of cosmetic products when used under normal or reasonably foreseeable conditions of use, as stated in Article 3 of the Cosmetics Regulation. Consequently, the restriction of substances in cosmetic products for human health concerns is exclusively regulated by the Cosmetics Regulation and the restriction process of REACH is only applicable to environmental concerns or to indirect human health concerns (Article 67.2 REACH).

\section{Actors involved in the restriction process}

The restriction process involves several actors, which all have a specific tasks and roles during the process. The microplastics restriction process started with a preparatory study in intentionally added microplastics by the Commission on request of the Member States, the EU Report on Microplastics. Both Member States and the Commission can take the initiative to prepare a restriction dossier, and in case the Commission is the initiator, ECHA has to prepare it. In the microplastics restriction process, ECHA has a leading role as compiler of the dossier, also called the restriction report. 
After the submission of the restriction dossier, the Committee for Risk Assessment (RA Committee) and the Committee for Socio-economic Analysis (SEA Committee) come into play. These committees check conformity of the dossier and give an opinion on the proposed restriction. The RA Committee consists of one or two member(s) of each EU Member State and currently includes 54 experts in fields such as (eco)toxicology, chemistry, and risk assessment (Article $85 \mathrm{REACH}$ ) [13]. Also the SEA Committee consists of one or two member(s) of each Member State and, at present, counts 36 members, with experts in the same fields as the RA Committee, complemented with experts in economics and law. Members of both committees are appointed by ECHA based on nominations of the Member States. There is also a small role for the Forum for Exchange of Information on Enforcement (Forum), composed of representatives of the Member States, which coordinates a network of Member States authorities responsible for enforcement of REACH. The Forum examines restriction proposals and gives an advice concerning enforceability (Article 77.4.h REACH).

In different stages of the process, interested parties will be asked to provide comments and evidence. Interested parties are, according to ECHA, citizens, organisations, companies as well as authorities of Member States. Manufacturers or importers of substances do not have a particular role in the restriction process and are treated as interested parties. After the publication of the registration dossier, the formal public consultation period starts, but also in the period of the preparation of the restriction report interested parties may be called upon to provide information.

The Commission has the task to prepare a decision on restriction and has the leading role in the legislative part, the regulatory procedure with scrutiny (Article $133.4 \mathrm{REACH}$ ) [14]. If so decided, it will draft the amendment to REACH, based on the proposal in the restriction report. A Scrutiny Committee, composed of representatives of the Member States, will give its opinion, and the draft amendment will be sent for voting to the European Parliament and the Council of the European Union, consisting of the relevant ministers of the Member States. After adoption of the restriction, the Member States are responsible for the enforcement of REACH.

\section{The restriction process}

The restriction process formally starts with a notification of intention of a Member State, a request of the Commission, or when ECHA decides itself after authorisation, to prepare a restriction dossier. ECHA listed the intention of submission of the restriction report on microplastics on 17 January 2018 after the request of the Commission to prepare such dossier on 9 November 2017. The listing of the notification by ECHA on 17 January 2018 should be considered as the date of the start of the restriction process on microplastics, as outlined in table 1. According to Article $69 \mathrm{REACH}$, within 12 months of the notification the restriction report should be submitted and published. For the restriction dossier on microplastics ECHA has set the date on 11 January 2019 for submission of the report. ECHA also made a call for comments and evidence on 1 March 2018, ending on 11 May 2018 [15]. During this period all interested parties are able to provide information on all possible intentional uses of microplastic particles in products in order to determine whether these uses pose a risk. This consultation does not replace the formal public consultation after the submission of the restriction report, but will help ECHA to develop the report and allows interested parties to signal their interest and express their views and concerns.

After submission of the restriction report, expected on 11 January 2019, the Committee for Risk Assessment (RA Committee) and the Committee for Socio-economic Analysis (SEA Committee) will check the restriction dossier on conformity with Annex XV REACH. Annex XV REACH includes the requirements of the registration dossier, including a proposal for restriction, which will be discussed in the next part. The checks should be done within 30 days, but if the dossier does not conform, an additional 15 days will be given to the committees for stating the reasons for non-conformity. Subsequently, the submitter is given 60 days to bring the restriction dossier in conformity with the requirements of Annex XV REACH. As the microplastics report is prepared by ECHA, it would be unlikely that it would not conform to its own standards. When the restriction report is considered conforming Annex XV REACH, ECHA will publish the report on its website. This date, for the microplastics report can be expected between 11 January 2019 - the announced date of submission - and 3 May 2019 - the latest date for submission of the restriction dossier in conformity with Annex XV REACH.

The publication date is a new benchmark in the restriction procedure, as it is the start of several simultaneous steps in the procedure. Both the RA Committee and SEA Committee will begin with the formulation of an opinion regarding the proposed restriction, and also the 6 -month period of public consultation starts. The RA Committee should finalise its opinion within nine months, while the SEA Committee should first prepare a draft opinion. The draft opinion is published and interested parties are invited to give their comments within 60 days. The final opinion of the SEA Committee should be adopted within 12 months of the publication date of the restriction dossier, in case of no delays that would be 11 January 2020. ECHA will publish the committee opinions, advice of the Forum, the comments received through public consultation as well as the response to the comments by the submitter of the restriction dossier and the committees. The Commission will then prepare its decision on the restriction dossier within three months and, if so decided, draft the amendment to Annex XVII REACH to include the restriction. For the microplastics dossier, the anticipated date would be 11 April 2020. The regulatory procedure with scrutiny will then start. The Scrutiny Committee delivers its opinion on the draft amendment, within a time-limit, laid down by the chair of the Committee. 


\begin{tabular}{|c|c|c|c|c|c|c|c|}
\hline 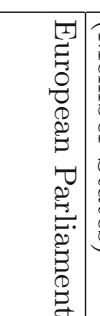 & 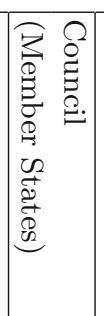 & 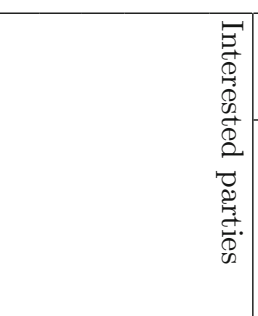 & 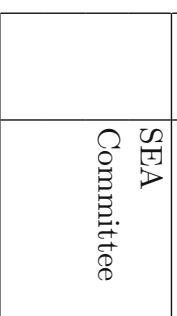 & 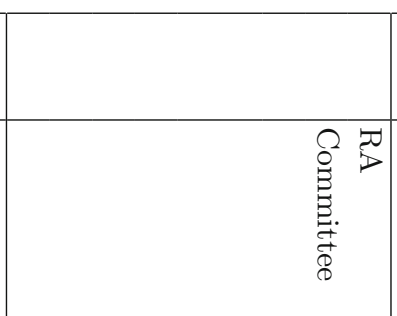 & 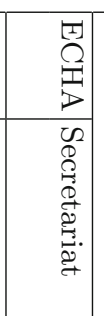 & 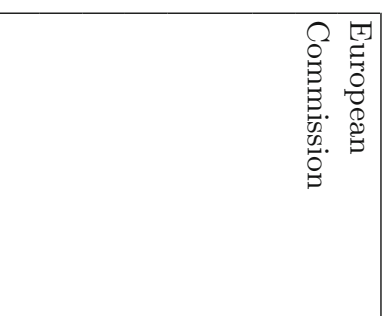 & 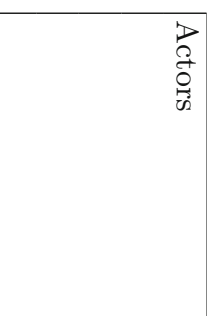 \\
\hline & & & & & & 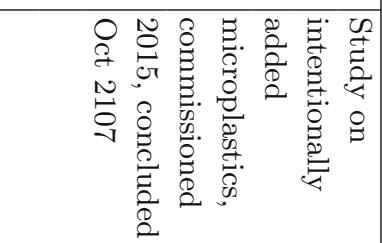 & 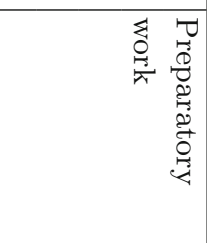 \\
\hline & & & & & & 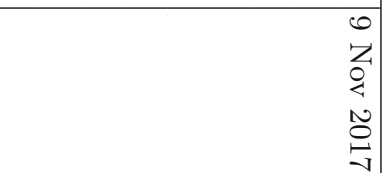 & 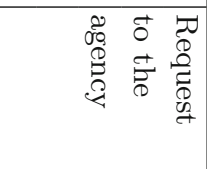 \\
\hline & & & & & 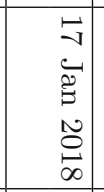 & & 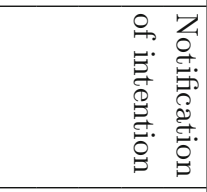 \\
\hline & & 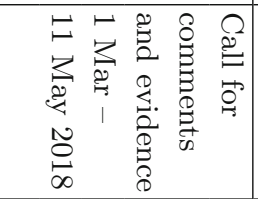 & & & 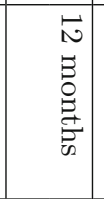 & & 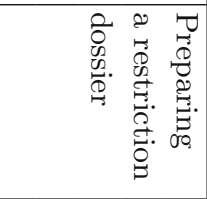 \\
\hline & & & & & 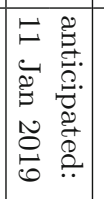 & & 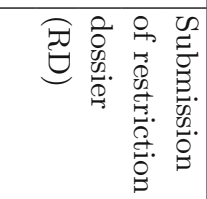 \\
\hline & & 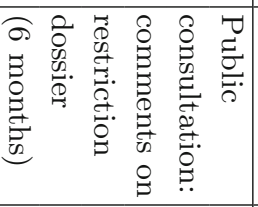 & 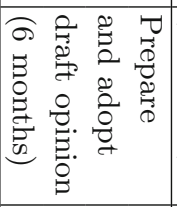 & 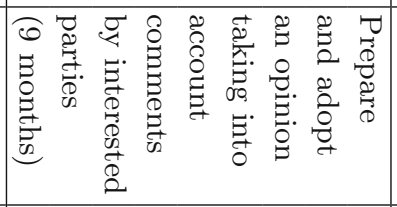 & & & 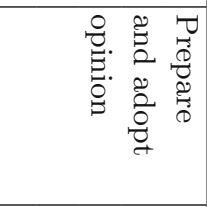 \\
\hline & & 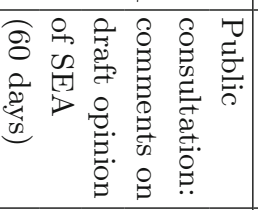 & 胥. & & & & 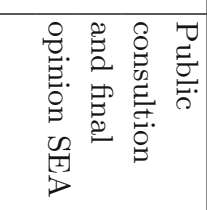 \\
\hline & & & 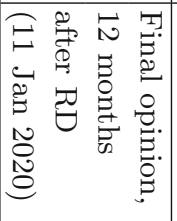 & 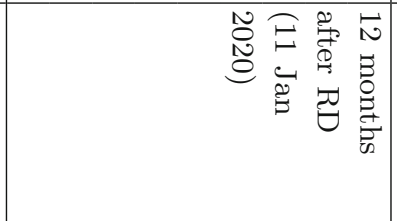 & & & 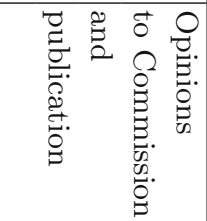 \\
\hline & & & & & & 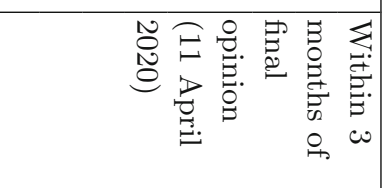 & 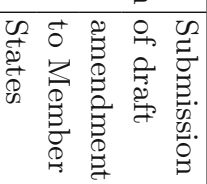 \\
\hline 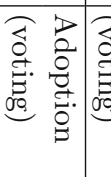 & 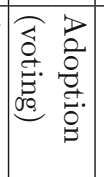 & & & & & 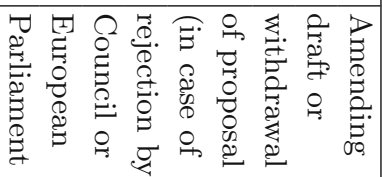 & 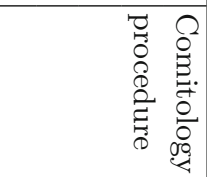 \\
\hline
\end{tabular}


Table 2. Format of a restriction dossier.

\begin{tabular}{|l|l|}
\hline Report & Annexes \\
\hline Summary & \\
\hline 1) The problem identified & Annex A. Manufacture and uses \\
& Annex B. Information on hazard, exposure/emissions and risk \\
& Annex C. Justification for action on a Union-wide basis \\
& Annex D. Baseline \\
\hline 2) Impact assessment & Annex E. Impact Assessment \\
\hline 3) Assumptions, uncertainties and sensitivities & Annex F. Assumptions, uncertainties and sensitivities \\
\hline 4) Conclusion & \\
\hline & Annex G. Stakeholder information \\
\hline
\end{tabular}

Then, the European Parliament and the Council will come in. There are different scenarios depending whether the draft measure is in accordance with opinion of the Scrutiny Committee or not [14]. At best, the Commission may adopt the draft amendment within three months if there is no opposition of the Council or European Parliament. But if there is opposition and/or the opinion of the Scrutiny Committee is not in accordance, majority voting in the Council and European Parliament is required, and if the proposed restriction is opposed, an amended proposal should be submitted by the Commission, and the regulatory procedure with scrutiny will be repeated. Therefore, it is impossible to predict when a restriction on microplastics may come into force.

\section{Restriction dossier on intentionally added microplastics}

The content of a restriction dossier is outlined in Annex XV of REACH. The dossier should consist information on six parts: proposal, information on hazard and risk, information on alternatives, justification for restrictions at Community level, socio-economic assessment, and information on stakeholder consultation. ECHA has published a guidance, which provides hands-on information for submitters of a restriction dossier, but also for interested parties [16]. The format of a restriction dossier has been updated in 2016 to provide a new structure and a rearrangement of the required information [17]. In the new format, the dossier includes a "report" containing the restriction proposal and supporting information, while detailed information is provided in "annexes", as outlined in table 2.

\subsection{Summary}

The cover page includes the chemical name of the substance(s), the IUPAC name(s), the EC number(s) ${ }^{1}$, and CAS number(s) if applicable. The summary introduces the scope and conditions of the restriction and includes the restriction proposed and a summary of the justification, based on the information provided in the subsequent parts of the restriction dossier. The proposed restriction is composed according to the table in Annex XVII REACH on restrictions and can directly be used as text for the amendment. However, if ECHA concludes that there is no need for a proposed restriction, this part explains why no restriction is proposed ${ }^{2}$.

\subsection{The problem identified}

This section starts with the hazard, exposure/emissions and risks, based on the information given in Annex A and B of the report. Providing the identity information of the substance(s), Annex B starts with information on the molecular and structural formula and the composition of the substance. It also includes a justification for grouping in case the restriction proposal covers more than one substance.

\footnotetext{
1 The EC number is the number which has been given in the EC Inventory, a combination of three lists under former European regulations: the European Inventory of Existing Commercial Chemical Substances (EINECS), the European List of Notified Chemical Substances (ELINCS) and the No-Longer Polymers (NLP) list, see ECHA, https://echa.europa.eu/informationon-chemicals/ec-inventory.

2 See, for example, the Annex XV reports on Grill lighters fluids and fuels for decorative lamps, labelled R65 or H304 (17 April 2015) and cadmium and its compounds (02 February 2015).
} 
The European Commission has identified more than 130 synthetic polymers that may be added as microplastics to products [3] and the first challenge is to determine the definition of microplastics for restriction. Although there may be various ways to make distinctions, such as differentiating between homopolymers and copolymers, and types of polymers [18], the discussion on definitions suggests, that, regarding microplastics in cosmetic products, a distinction between functions, solid and not solid, and solubility in water can be made. Guidance within REACH can be found in Annex XI of REACH, providing that the physicochemical, toxicological and ecotoxicological properties are likely to be similar or follow a regular pattern as a result of structural similarity. For grouping REACH requires that those properties and human health and environmental effects or fate may be predicted from data for reference substance(s) within the group by interpolation to other substances in the group, the read-across approach. Grouping is also possible for related substances if the key property in combination with the exposure that causes the risk leading to the restriction proposal is shared by those related substances [16].

Since the compiling of the restriction dossier is triggered by national initiatives, in particular the French prohibition, a look at the definition of the substance in this regulation is justified. The French legislation does not refer to specific substances but defines microplastics as "particules plastiques solides, à l'exception des particules d'origine naturelle non susceptibles de subsister dans les milieux, d'y propager des principes actifs chimiques ou biologiques ou d'affecter les chaînes trophiques animales", in English "solid plastic particles, with the exception of particles of natural origin not liable to persist in the environment, release active chemical or biological ingredients thereinto, or affect animal food chains" [19]. This definition in turn was based on the definition of the US Microbead-Free Waters Act of 2015, which defines a microbead as any solid plastic particle that is less than five millimeters in size and is intended to be used to exfoliate or cleanse the human body or any part thereof [20]. These definitions more or less group all solid synthetic polymers. The French definition explicitly excludes polymers of natural origin, with the condition that these are not harmful for the environment. The US definition, though, includes the function of the microplastics: exfoliating and cleansing, excluding microplastics that have other functions. In literature, microplastics are defined as synthetic, nondegradable, water insoluble, solid materials made up of polymers. They are often made of petroleum carbons source and a distinction can be made between thermoplastics and thermoset plastics, and between homopolymers and copolymers $[21,22]$. It is noted that cosmetics products also may include synthetic polymers that are liquid at ambient temperature or water soluble, but these substances are generally not considered as microplastics [3]. Regarding the functions, microplastics are added for exfoliating and cleansing, but also for film formation, viscosity regulation, skin conditioning, emulsion stabilizing, opacifying, bulking, glittering, functions that go beyond the US definition [3,22]. The EC Report on Microplastics established the following working definition:

- Microplastics consist of man-made, conventional plastics.

- Microplastics also include bio-degradable plastics, bio-based analogue plastics, and biobased alternative plastics.

- Microplastics are solid and water-insoluble particles.

- Microplastics have particle size below $5 \mathrm{~mm}$ and include nanometer sized plastics as well (nanoparticles).

Through the exemption of polymers from registration, REACH has more or less "grouped" polymers. The exemption has also resulted in the fact that not all polymers have an EC number and information on polymers is limited within the REACH system. For example, a frequent used type of microplastic in cosmetic products is Acrylates Copolymer, which is a group of polymers containing monomers acrylic acid or methacrylic acid or one of their salts or esters [23]. As an ingredient for cosmetic products, Acrylates Copolymer is included in CosIng, the EC Cosmetic ingredient database for information on substances and ingredients [24]. The file for Acrylates Copolymer in CosIng specifies three CAS numbers and IUPAC names, while the US Cosmetic Ingredient Review on Acrylates Copolymer includes over thirty groups of Acrylates Copolymer ${ }^{3}$. Since Acrylates Copolymer has no EC number, no information regarding molecular formula and composition is available in the EC Inventory ${ }^{4}$.

Annex B follows the Chemical Safety Report (CSR) format, described in Annex I of REACH. This Annex sets the requirements for assessment of hazard and risk assessments and provides a format for compiling a CSR. It should also include substance identification parameters, which are regulated in Article 10 of REACH, setting the information standards for registration. As polymers are exempted from registration, the information for the microplastics dossier

\footnotetext{
3 25133-97-5 / 25035-69-2 / 25212-88-8, 2-propenoic acid, 2-methyl-, polymer with ethyl 2-propenoate and methyl 2-methyl2-propenoate, see CosIng, http://ec.europa.eu/growth/tools-databases/cosing/index.cfm; Cosmetic Ingredient Review, Final report of the safety assessment of acrylates copolymer and 33 related cosmetic ingredients, in International Journal of Toxicology, Vol. 21 (2002) p. 1; https://www.cir-safety.org/ingredients. The US Cosmetic Ingredient Review, an initiative of the Personal Care Products Council, an industry trade association, carried out a review of Acrylates Copolymer in 2002, and is currently working on an update. Registration of ingredients is totally voluntary in the US and it is the responsibility of the manufacturer to ensure that cosmetic products are safe. See further: Cosmetic Ingredient Review Procedures, October 2010, http://www.cir-safety.org/sites/default/files/pdf1.pdf; U.S. Food \& Drug Administration, Voluntary Cosmetic Registration Program, https://www.fda.gov/Cosmetics/RegistrationProgram/default.htm.

${ }^{4}$ EC Inventory, https://echa.europa.eu/information-on-chemicals/ec-inventory (search for Acrylates Copolymer gives no results).
} 
Table 3. Criteria for persistence according REACH Annex XIII as part of PBT/vPvB criteria.

\begin{tabular}{|l|l|l|}
\hline Compartment & Persistent: half-life days & Very persistent: half-life days \\
\hline Marine water & $>60$ days & $>60$ days \\
\hline Fresh or estuarine water & $>40$ days & $>60$ days \\
\hline Marine sediment & $>180$ days & $>180$ days \\
\hline Fresh or estuarine water sediment & $>120$ days & $>180$ days \\
\hline Soil & $>120$ days & $>180$ days \\
\hline
\end{tabular}

Table 4. Criteria for bioaccumulation according REACH Annex XIII as part of PBT/vPvB criteria.

\begin{tabular}{|l|l|l|}
\hline & Bioaccumulative & Very bioaccumulative \\
\hline Bioconcentration factor in aquatic species & $>2000$ & $>5000$ \\
\hline
\end{tabular}

should be collected from other sources, such as safety data sheets. Chemical Safety Reports may be compiled for a group of substances, based on the same criteria used for the identification of substances as discussed above. Often an overview of studies in literature will be presented, especially when no or limited information is presented by manufacturers in registration dossiers and safety data sheets. Manufacturers and importers of substances, including polymers, have to provide downstream users with a safety data sheet if the substance can be classified as hazardous under the CLP Regulation, as a PBT or a $\mathrm{vPvB}_{\mathrm{v}}$, or when it is on the list for authorisation (Article $31 \mathrm{REACH}$ ). However, these are not publicly available and the accuracy is the sole responsibility of the manufacturer or importer. A CSR includes ten sections: 1) identity of the substance; 2) manufacture and uses; 3) classification and labelling; 4) environmental fate properties; 5) human health hazard assessment; 6) human health hazard assessment of physicochemical properties; 7) environmental hazard assessment; 8) PBT and vPvB assessment; 9) exposure assessment; and 10) risk characterisation.

1) Information on the identity of the substance, including physical and chemical properties should be provided. Issues regarding the identification of microplastics, such as the possibility of grouping, have been discussed above.

2) Information on manufacture and uses is based on Annex A of the restriction dossier. Annex A should identify quantity of manufacture and uses of the substances, on its own, in products and mixtures, and also include the uses advised against. The EC Report on Microplastics provides detailed information on the use of microplastics in cosmetic products, but only limited data on microplastics in other products, such as paints and coating, detergents, and other uses. This part can be supplemented with information from interested parties, such as manufacturers and downstream users, but also scientists.

3) If the substance is listed according the CLP Regulation, it should be noted in the section on classification and labelling. A quick review shows that not many polymers have been classified or labelled. Also, the previous mentioned frequently used microplastic Acrylates Copolymer is not listed.

4) The environmental fate properties must be described. Environmental fate properties that should at least be assessed include degradation (abiotic degradation, biodegradation), environmental distribution, bioaccumulation and secondary poisoning, including contamination of the food chain. Practice shows that these properties can be complemented with other properties or more detailed properties if appropriate. The scientific research on these topics should be reviewed in this part.

5) Human health hazard assessment is comprised of 11 properties: toxicokinetics (absorption, metabolism, distribution, elimination), acute toxicity, irritation, corrosivity, sensitisation, repeated dose toxicity, germ cell mutagenicity, carcinogenicity, toxicity for reproduction, other effects, derivation of DNEL). It should be noted that the restriction procedure on microplastics cannot apply to human health risks resulting from the normal use of cosmetics, and that these issues should be addressed through the Cosmetics Regulation.

6) The human health hazard assessment of physicochemical properties consists of explosivity, flammability and oxidising potential.

7) Environmental hazard assessment considers the potential effects on the environment, in particular the aquatic compartment, terrestrial compartment, atmospheric compartment and the microbiological activity in sewage treatment systems. It should identify the concentration of the substance below which adverse effects in the environment are not expected to occur, the Predicted No-Effect Concentration (PNEC). In the EC study on intentionally added microplastics, the authors distinguish physical and toxic effects. The assessment is wholly based on literature review and comes to some cautious conclusion that there is some evidence for the potential for toxic effects as well as physical effects to be exhibited on exposure of environmental organisms to microplastics [3]. It also points out that is it not possible to establish a PNEC at this stage, due to the different parameters used in studies and the wide range of effects. 
8) The objective of the PBT and $\mathrm{vPvB}_{\mathrm{v}}$ assessment is to determine whether a substance is persistent, bioaccumulative and toxic, or very persistent and very bioaccumulative according to the criteria in Annex XIII REACH. A substance is persistent or very persistent if it fulfils any of the half-life values in table 3 . Table 4 presents the criteria for bioaccumulation. Further details can be found in Annex XIII REACH. Also in this part of the dossier, scientific evidence should be reviewed.

9) According to Annex I REACH, the exposure assessment requires a quantitative or qualitative estimate of the dose/concentration of the substance to which humans and the environment are or may be exposed. The assessment should consider all stages of the life-cycle of the substance resulting from the manufacture and identified uses and should cover any exposures that may relate to the hazards identified just above. Two steps can be distinguished: development of exposure scenarios and exposure estimation.

The EC Report on Microplastics states that an approach to exposure estimate using EUSES (European Union System for the Evaluation of Substances) represented a practicable and understandable method as the model is well understood by European regulatory authorities and industry experts alike, and that it can be reasonably easily adapted for estimation of the environmental distribution of microbeads for this project [3]. The report concludes that, notwithstanding uncertainties, certain uses of microplastics appear to lead to notable concentrations in environmental compartments, though it would be impossible to say whether these are significant in terms of environmental impact. As pointed out above, interested parties are able to provide ECHA with relevant information. This section should also include an assessment of the risk management measures, including any existing legal requirements, and the effectiveness thereof. Included should be national measures, voluntary agreements and international initiatives. Most obvious in relation to microplastics in cosmetic products is the prohibition of microplastics as emission from cosmetics products cannot be prevented, though the ECHA Guidance for restriction dossiers suggests a broad approach to provide the essential information for the section on justification for restrictions at Community level, which will be examined below. For microplastics in other products other measures could be appropriate to prevent emission to the environment. Regarding microplastics in cosmetic products in the EU, so far only the French legislation has taken effect on the use of microplastics in cosmetic products by consumers, though its ban is based on a limited definition applicable to only rinse-off products. The EC Report on Microplastics suggests a decrease due to voluntary action taken by the cosmetics industry. However, part of these analyses is based on research by Cosmetics Europe in 2012 [25], which was only surveying polyethylene microplastics used for exfoliating and scrubbing, leaving out all other microplastics with other functions. The suggested decrease could be explained by using alternative polymers, which were not included in the survey. On the international level, the United Nations Environment Programme, in the Draft resolution on marine litter and microplastics [26], has acknowledged microplastics as a serious threat to the environment and calls upon international organisation, states, the private sector and civil society to take action.

10) The information on risk characterisation is closely related to the exposure assessment as it requires a risk characterisation for each exposure scenario. It shall consider the human population (as workers, consumers or indirectly via the environment). For microplastics, direct exposure to substances in cosmetic products is excluded from restriction under REACH, however indirect exposure via contamination in water and food should be taken into account.

The practice of restriction dossiers demonstrates that the information in this part of the dossier can be based on extensive literature review and information of interested parties. ECHA has made a call to provide evidence and information on the intentional uses of microplastic particles in products of any kind [15]. ECHA stipulates that the scope of the investigation is very wide and that all relevant products, including rinse-off and leave-on cosmetic products will be investigated.

The justification for an EU wide restriction measure should also be included in this part, requiring that i) action is required on a union-wide basis, and ii) a restriction is the most appropriate community-wide measure with regard to effectiveness, practicality, and monitorability, with further details in Annex C. The restriction should be considered against the objectives of REACH, human health and environment protection, as well as free circulation of substances on the internal market. For the restriction dossier on microplastics, focus will be foremost on environmental aspects, since the threat to the aquatic environment was identified as the main concern by the European Commission. Both in the marine environment as in freshwater systems, microplastics are a major source of pollution $[27,28]$. Oceans, rivers and lakes transport microplastics, even to the most remote areas of the earth. The transboundary exposure to microplastics is a consideration for action on a union-wide base, which should lead to a substantial reduction of intentionally added microplastics. Since removing microplastics from the aquatic environment is extremely difficult and costly, or even impossible, prevention is identified as the most effective option [29]. Acknowledgement of the fact that intentionally added microplastics are only a fraction of all emitted microplastics to the environment, a restriction might nevertheless effectively tackle this particular fraction, notwithstanding the need for regulation on other emitted microplastics.

This section continues with considerations regarding the working of the internal market, as the restriction pertains to the adding of microplastics to products, which are subject to the free movement of goods principle. In Article 9 of the Cosmetic Regulation, on free movement, it is stipulated that member states shall not restrict cosmetic 
products which comply with the requirements. Also REACH includes a roughly similar provision in Article 128 . The free movement of goods is a pillar of the European Union and prohibits unjustified restrictions by member states. At the same time, it is the underlying principle of harmonisation of technical standards as key component in EU law. This is confirmed in case law regarding REACH, in which the Court stated that harmonisation is a result from a finalised restriction process [30]. The Court also pointed out that national measures trigger the restriction procedure, in order to harmonise standards. In its request for a restriction proposal, the European Commission referred to national initiatives banning the use of microplastics and these circumstances contribute to the justification of a restriction on union level. Without harmonised standards, in the form of a restriction, member states would be able to institute their own restrictions, possibly leading to a patchwork of standards.

The third section in this part of the report should contain information on the baseline, the business as usual scenario, further detailed in Annex D, which may be used for the next part of the report, the impact assessment.

\subsection{Impact assessment}

This part of the dossier should provide information on all potential impacts, with a qualitative and quantitative assessment of the impacts, and monetisation thereof. Annex E provides the detailed information and the first section deals with the risk management options (RMOs). RMOs are any possible changes to legislation or other requirements to industry to control risks, including the proposed restriction but also, for example, other restrictions based on other regulation, and economic instruments and voluntary agreements. The second section describes alternative substances. Annex XV prescribes that available information on alternative substances and techniques shall be provided, including: - information on the risk to human health and the environment related to the manufacture or use of the alternatives, - availability, including the time scale, and, - technical and economical feasibility.

Annex E also contains a description of restriction scenarios, economic impacts, human health and environmental impacts, and other impacts, such as social impacts and wider economic impacts, which can be seen as a socio-economic assessment as required by Annex XV REACH. This section of the dossier has been labelled as an enormous difficult task [31]. The restriction report expects a description of at least two restriction options, which are assessed and compared in detail.

The EC Report on Microplastics includes a twenty-page review of alternatives in a wide range of products. For microplastics in cosmetic products, focus is on scrub and exfoliating functions, however the report notes that widening of the definition and the scope of restriction may lead to thousands of alternatives to be assessed. Two scenarios of restrictions, based on different definitions of microplastics, are put forward. Scenario 1 is based on the restriction of microplastics as a solid, no soluble plastic particle, both in rinse-off and leave-on products. Based on information from Cosmetic Europe and the European Federation for Cosmetic Ingredients (EFfCI), the EC Study concludes that this scale of costs is unlikely to be affordable.

Scenario 2 would involve a restriction covering all polymers. Based on information provided by EFfCI, it would follow that virtually all classes of cosmetic products would be affected. According to the industry, most formulations would no longer be feasible, while alternative technologies are not available and would take years/decades to develop (if at all possible). Financial information is mostly based on calculations of the industry, in particular the reformulation costs of products, and costs are estimated in the worst case at some $€ 5.2$ billion annually. Although taking into account variabilities and uncertainties, the EC Report on Microplastics points out that the potential costs of a restriction are potentially very significant. The report concludes that it is not considered possible to demonstrate that the net benefits of a restriction to health and the environment would outweigh the net costs to the industry and consumers at the present time [3].

Conclusions in the impact assessment chapter are used in developing the justification that the proposed restriction is the most appropriate measure, especially in the light of effectiveness and practicality. Which assessment weights more is unclear, though the hierarchy will determine largely the conclusions on justification [31]. The information also provides a basis for the opinion of the SEA Committee. Therefore, it is essential that further information from interested parties is presented, which may complement the information or even counter the assumptions in the EC Report on Microplastics. For example, there are already more than fifty cosmetic companies that do not use microplastic ingredients in all of their products [32], proving that there are readily available alternatives for competitive prices, which may reduce the reformulation costs significantly.

\subsection{Assumptions, uncertainties and sensitivities}

In this chapter of the restriction report the main assumptions should be described, as well as the uncertainties. Uncertainties can be noted in all kinds of information, from quantities in use and of emissions, to estimates and calculation of costs. As we have seen in the previous chapter, if only information of one particular source is available, assessments will be largely based on this information, and therefore could be incomplete or even biased. This part could also indicate a request for further information from stakeholders to test assumptions or reduce uncertainties. 
A gap in scientific data may also trigger the application of the precautionary principle. Its purpose is to make greater allowance for uncertainty and it may result in a shift of the burden of proof $[33,34]$. However, no mentioning of the precautionary principle is made in any of the guidance documents of ECHA. A review of restriction dossiers reveals that the precautionary principle does not play a role in the assessment and justification of restrictions. It seems to be a missed opportunity and may possible prevent restrictions in situations of uncertainty [34]. Regarding the certain uses on microplastics, the EC Report on Microplastics concludes that for the use of microplastics in the oil and gas industry, hardly any scientific data is available [3]. No further analyses of these uses are made in the report, and it seems unlikely that a restriction would cover these uses, while the potential of contamination of these uses may be as severe as other uses.

\subsection{Conclusion and information on stakeholder consultation}

The report ends with a conclusion stating shortly the proposed restriction and the justifications. Annex G in the Annexes part refers to stakeholder contacts, and the methods employed, ranging from calls for evidence to direct consultation and participation in meetings. This pertains to informal consultation, as the formal consultation starts after the submission of the restriction dossier.

As mentioned above, ECHA made a call for evidence and information regarding the restriction dossier and ECHA particular welcomed information on the definition of microplastics, the specific uses, the functions, the alternatives and socio-economic impacts. Furthermore, it asked for information on analytical methods for detecting and characterising microplastic particles in products.

Compiling a restriction dossier according to the requirements described above, is a time-consuming and complex task. Guidance is provided by ECHA, but as result of the large quantity of information to supply and the details required, it seems almost impossible to collect and assess the information within a year. Practically, the European Commission has stretched this period regarding the restriction dossier on microplastics by first commissioning a study with similar sections, which resulted in the EC Report on Microplastics. Nevertheless, it remains a daunting task to prepare a restriction dossier on microplastics, given the number of polymers, the lack of registration dossiers, the various functions and uses of microplastics, the numerous products that contain microplastics, great quantity of dispersed scientific information, and the number of required assessments, in particular hazard, impact, risk and socio-economic assessments.

\section{Furthers steps in the restriction procedure}

As outlined above, after submitting the restriction dossier, both the SEA and RAC Committees prepare an opinion, and interested parties are able to provide comments. At any time, the European Commission is able to withdraw the restriction proposal. After this period it is up to the European Commission to draft the amendment for inclusion of a restriction in Annex XVII of REACH, and guide it through the regulatory procedure. When a restriction is adopted and published, usually a phase out period will start, so industry can adjust its substances and products for compliance. Enforcement is a task for member states. Each member state should implement the REACH restriction into its national legislation and set sanctions for non-compliance. National authorities may carry out inspections, which could be coordinated and guidance of ECHA. However, the main responsibilities are with the national authorities, as ECHA has not enforcement powers.

Restrictions may be amended, through the same procedure, so by compiling again a restriction dossier. Also provisional measures may be taken in case of urgent action is essential to protect human health or the environment (Article $129 \mathrm{REACH}$ ), which would trigger the restriction procedure for amendment.

\section{Concluding remarks}

This article has attempted to describe the restriction process and the contents of the restriction dossier, while addressing the issue of scientific input. The procedure is complex and lengthy, with several consultations of interested parties in different phases. Scientific experts are able to provide evidence in both informal and formal positions, as interested parties, but also as members of the RA or SEA Committees.

Although following an outlined format and guidance by ECHA, the compilation of a restriction dossier remains an enormous task, especially the preparation of the assessments, such as the socio-economic assessment. The submitter of the dossier is highly dependent on data that is available from interested parties, as it seems to be impossible to carry out such an assessment from scratch within a year [16]. The content and format of the dossier clarifies that the objectives of REACH - human health and environmental protection on one side, and regulation of the internal market on the other side - go hand in hand. The free movement of substances and products is an essential aspect in the drafting of the restriction proposal, the actual amendment. Even the abundance of scientific data on hazards and environmental fate does not guaranty regulatory measures: the restriction must also be justified on the basis of the socio-economic assessment. The EC Study on Microplastics strikingly points out that economic considerations may substantially affect the justification for restrictions as the costs aspects put a heavy weight in the balancing act [3]. 
In the case of insufficient scientific data, it seems that the precautionary principle does not play a significant role in the restriction procedure, even though it is part of the objectives of REACH. It is presumed that data gaps would rather lead to "less than more" justification of a restriction. For the restriction dossier on microplastics is therefore of utmost importance that all available evidence is provided. When less data is available, restriction seems to be less likely.

My final remark concerns the importance of political will. Plastic pollution has recently drawn a lot of public and political attention and the momentum for further regulation of plastics is there [4]. In the end, it is up to the European Commission, together with the Council and the European Parliament, to make the final decision on a restriction on microplastics.

Open Access This is an open access article distributed under the terms of the Creative Commons Attribution License (http://creativecommons.org/licenses/by/4.0), which permits unrestricted use, distribution, and reproduction in any medium, provided the original work is properly cited.

\section{References}

1. Council Regulation (EC) 1907/2006 on the Registration, Authorisation and Restriction of Chemicals (REACH) [2006] OJ L 33/1.

2. European Commission, Note for the attention of Mr G. Dancet, Executive Director, ECHA, 9 November 2017, Ref. Ares (2017) 5463573.

3. EC, Intentionally added microplastics in products: final report (European Commission, Brussels, 2017).

4. Communication from the Commission to the European Parliament, the Council, the European Economic and Social Committee and the Committee of the Regions, A European Strategy for Plastics in a Circular Economy, SWD (2018) 16 final, COM (2018) 28 final 16 January 2008.

5. EU Survey, Investigating options for reducing releases in the aquatic environment of microplastics emitted by (but not intentionally added in) products, https://echa.europa.eu/hot-topics/microplastics.

6. C.M. Rochman, A.M. Cook, A.A. Koelmans, Environ. Toxicol. Chem. 35, 1617 (2016).

7. E. Fisher, J. Risk Res. 11, 541 (2008).

8. Regulation 1272/2008/EC of 16 December 2008 on Classification, Labelling and Packaging of Substances and Mixtures, [2008] OJ L353/1.

9. L. Bergkamp, The European Union REACH Regulation for Chemicals: Law and Practice (Oxford University Press, 2013).

10. E. Fisher, Rev. Eur. Comp. Int. Environ. Law 23, 163 (2014).

11. OECD, Data analysis of the identification of correlations between polymer characteristics and potential for health or ecotoxicological concern (OECD, Paris, 2009).

12. Regulation (EC) 1223/2009 of the European Parliament and of the Council on cosmetic products OJ L342/59 (Cosmetics Regulation).

13. ECHA, Committee for Risk Assessment, https://echa.europa.eu/about-us/who-we-are/committee-for-riskassessment.

14. Council Decision of 28 June 1999 laying down the procedures for the exercise of implementing powers conferred on the Commission (1999/468/EC) OJ L 184, Articles 5a and 7.

15. ECHA, Call for evidence on the use of intentionally added microplastic particles in products of any kind, 1 March 2018, https://echa.europa.eu/calls-for-comments-and-evidence/-/substance-rev/19224/term.

16. ECHA, Guidance for the preparation of an Annex XV dossier for restrictions (ECHA, 2007).

17. ECHA, Addendum to the guidance on Annex XV for restrictions and the guidance on socio-economic analysis (SEA) restrictions, Format of Annex XV restriction report, Version 2.1, 17 May 2016.

18. A.J. Verschoor, Towards a Definition of Microplastics - Considerations for the Specification of Physico-Chemical Properties (RIVM, 2015).

19. Loi $\mathrm{n}^{\circ}$ 2016-1087 du 8 août 2016 pour la reconquête de la biodiversité, de la nature et des paysages, TA $\mathrm{n}^{\circ} 803$, http://www assemblee-nationale.fr/14/ta/ta0803.asp, Translation provided by Isaure Simonin, student of the Leiden Advocacy Project on Plastic.

20. H.H.R. 1321 -Microbead-Free Waters Act of 2015, 114th Congress (2015-2016), https://www.congress.gov/bill/114thcongress/house-bill/1321.R.1321.

21. H.A. Leslie, Review of Microplastics in Cosmetics (IVM Institute for Environmental Studies, Amsterdam, 2014).

22. UNEP, Plastic in Cosmetics: Are we Polluting the Environment through our Personal Care? (UNEP, 2015).

23. Final Report on the Safety Assessment of Acrylates Copolymer and 33 Related Cosmetic Ingredients, in International Journal of Toxicology, Vol. 21 (Suppl. 3), 1 (2002) https://doi.org/10.1080/10915810290169800.

24. EU, Cosing, https://ec.europa.eu/growth/sectors/cosmetics/cosing_en.

25. T. Gouin et al., SOFW J. 141, 40 (2015).

26. UNEP, Draft resolution on marine litter and microplastics, 5 December 2017, UNEP/EA.3/L.20.

27. A.L. Andrady, Mar. Pollut. Bull. 62, 1596 (2011). 
28. S. Lambert, M. Wagner, in Freshwater Microplastics: Emerging Environmental Contaminants?, edited by M. Wagner, S. Lambert (Springer International Publishing, Cham, 2018).

29. P.K. Cheung, L. Fok, Mar. Pollut. Bull. 109, 582 (2016).

30. EFTA, Case E-9/2016.

31. S. Vaughan, EU chemicals regulation: new governance, hybridity and REACH (Edward Elgar Publishing, Cheltenham, England, 2015).

32. Look for the Zero, http://www. beatthemicrobead.org/look-for-the-zero/.

33. P. Birnie, A. Boyle, C. Redgwell, International law and the environment (OUP, Oxford, 2009).

34. C. Calliess, H. Stockhaus, J. Eur. Environ. Plan. Law 9, 113 (2012). 